\title{
On the drivers of profitability in the banking industry in restructuring times: a Bayesian perspective
}

Paula Cruz-García

Department of Economic Analysis, University of Valencia, Valencia, Spain

Anabel Forte

Department of Statistics and Operational Research, University of Valencia, Valencia, Spain, and

Jesús Peiró-Palomino

Department of Applied Economics II and INTECO, University of Valencia, Valencia, Spain
Profitability in the banking industry

Received 19 January 2020 Revised 28 April 2020 29 April 2020 Accepted 29 April 2020

\begin{abstract}
Purpose - There is abundant literature analyzing the determinants of banks' profitability through its main component: the net interest margin. Some of these determinants are suggested by seminal theoretical models and subsequent expansions. Others are ad-hoc selections. Up to now, there are no studies assessing these models from a Bayesian model uncertainty perspective. This paper aims to analyze this issue for the EU-15 countries for the period 2008-2014, which mainly corresponds to the Great Recession years.
\end{abstract}

Design/methodology/approach - It follows a Bayesian variable selection approach to analyze, in a first step, which variables of those suggested by the literature are actually good predictors of banks' net interest margin. In a second step, using a model selection approach, the authors select the model with the best fit. Finally, the paper provides inference and quantifies the economic impact of the variables selected as good candidates.

Findings - The results widely support the validity of the determinants proposed by the seminal models, with only minor discrepancies, reinforcing their capacity to explain net interest margin disparities also during the recent period of restructuring of the banking industry.

Originality/value - The paper is, to the best of the knowledge, the first one following a Bayesian variable selection approach in this field of the literature.

Keywords Bayesian variable selection, Net interest margin, INLA

Paper type Research paper

(C) Paula Cruz-García, Anabel Forte and Jesús Peiró-Palomino. Published in Applied Economic Analysis. Published by Emerald Publishing Limited. This article is published under the Creative Commons Attribution (CC BY 4.0) licence. Anyone may reproduce, distribute, translate and create derivative works of this article (for both commercial and non-commercial purposes), subject to full attribution to the original publication and authors. The full terms of this licence may be seen at http:// creativecommons.org/licences/by/4.0/legalcode

Authors acknowledge the financial support of the Spanish Ministry of Economy and Competitiveness (ECO2017-84858-R, ECO2017-85746-P and MTM2016-77501-P). Jesús Peiro-Palomino is also grateful to the University Jaume I (UJI-B2017-33) and Anabel Forte is also grateful to Consejería de Educacion, Cultura y Deportes (JCCM, Spain) (SBPLY 17/180501/000491). The usual disclaimer applies.

JEL classification - G21, C11, C52

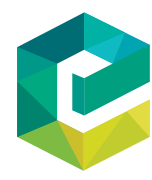

Applied Economic Analysis Vol. 28 No. 83,2020 pp. $111-131$

pp. $111-131$
Emerald Publishing Limited 2632-7627 DOI 10.1108/AEA-01-2020-0003 
AEA

28,83

\section{Introduction and motivation}

Since the outbreak of the financial crisis more than a decade ago, several factors have narrowed banks' net interest margin of new operations, which is their main source of earnings. This indicator corresponds to the difference between the interest rates that banks charge for new loans granted and the interest rates that they pay for new deposits. Central banks implemented expansive monetary policies to mitigate the negative effects of the crisis, resulting in a long-lasting period of low (or even negative) interest rates. Consequently, net interest margins have been severely affected. This is due to the existence of an effective lower limit on the remuneration of deposits - customers are not expected to accept a negative deposit interest rate - that makes difficult to transfer the decline in interest rates to the interest on deposits. Consequently, the financial margins narrow (Borio et al., 2017; Cruz-García and Fernández de Guevara, 2020; Angori et al., 2019), among others.

In addition, competitive conditions in the banking industry have changed. In Europe, the progress toward the banking union may have affected banks' margins negatively through increased competition. However, the same restructuring process of the banking sector in most of the European Union (EU) countries has led to augmented concentration in the banking industry, increasing banks' market power. In fact, in a press release in May 2018 the European Central Bank (ECB) reported that market concentration increased remarkably since the start of the restructuring process in 2008, reaching a historical maximum in 2017. The greater concentration of banking activity can be detrimental to long-term competition, as the increase in concentration might spur banks' margins through greater market power. In this turbulent scenario, the understanding of the determinants of banks' net interest margins is, therefore, particularly interesting.

One of the seminal and most widely used models to analyze this issue was developed by Ho and Saunders (1981). In that model, banks are considered risk-averse dealers in the credit market, acting as intermediaries between demanders and suppliers of lendable funds. This model assumes that the optimum pure bank interest margin depends on the banking market structure (intensity of competition), the degree of risk aversion of the bank, the average size of banks' transactions and the volatility of the interest rate. This seminal model has been subsequently expanded. McShane and Sharpe (1985) changed the source of interest rate risk from the risk of the interest rates of loans and deposits to the uncertainty in the money markets. Allen (1988) expanded the model by incorporating different types of loans. Angbazo (1997) included credit risk in addition to interest rate risk. In a subsequent expansion, Maudos and Fernández de Guevara (2004) included the operating costs and Carbó and Rodríguez (2007) extended the theoretical model by incorporating the importance of non-traditional activities [1]. Entrop et al. (2015) modified the model by including different types of assets in terms of their maturity and, finally, Cruz-García and Fernández de Guevara (2020) included the capital requirement and the deposit insurance premium.

Although the Ho and Saunders' (1981) framework is not the only model analyzing the determinants of banks' net interest margin [2], it has been the most used by the specialized literature. Accordingly, the number of empirical contributions using that framework and its subsequent expansions is vast. Some of them include Williams (2007), who follows McShane and Sharpe (1985) to analyze the determinants of net interest margin in Australia and the differences between domestic and foreign banks between 1989 and 2001. Following Carbó and Rodríguez (2007), Lepetit et al. (2008) analyze the effect of non-traditional fee-based activities on net interest margins. Nguyen (2012) focuses on the determinants of net interest margin and the determinants of the margin derived from non-traditional activities. Other studies have used expansions of the Ho and Saunders' (1981) model (generally those by Angbazo (1997) and Maudos and Fernández de Guevara (2004)) to assess banks' margins in 
particular countries or geographical areas. This list includes among others, Kannan et al. (2001) for India; Fernández de Guevara (2004) for Spain; Doliente (2005) for four Southeast Asian countries; Liebeg and Schwaiger (2006) for Austria; Claeys and Vander Vennet (2008) for a comparison between Central and Eastern Europe and Western Europe; Zhou and Wong (2008) for China; Maudos and Solís (2009) for Mexico; Lin et al. (2012) for Asian banks; Saad and El-Moussawi (2012) for Lebanon; Amuakwa-Mensah and Marbuah (2015) for Ghana; and Birchwood et al. (2017) for Central America and the Caribbean. Apart from the theoretical models in which they are based on, these papers have in common their econometric approach, relying on the frequentist branch of the statistical theory. Moreover, their findings generally corroborate the theoretical predictions. However, recent studies such as Bustos-Contell et al. (2019) argue that the fundamentals regarding the determinants of the net interest margin might have changed. In this context, further research is justified.

Against this background, this paper pursues a twofold objective. First, it aims to assess from a Bayesian perspective if the variables postulated by the Ho and Saunders' (1981) seminal model, its two most followed expansions (Angbazo (1997) and Maudos and Fernández de Guevara (2004)) and other variables that are included traditionally ad-hoc by the literature are actually good predictors of the net interest margin. This framework is the most widely used in the literature on banks' margins [3].

Despite the models are theoretically well-grounded and the results from empirical applications are mostly aligned with the models' predictions, their assessment from a Bayesian model uncertainty perspective can help to reinforce their position in the literature as appropriate benchmark models. The use of Bayesian statistics has become a relatively common practice in other fields of the economic literature. For instance, considering the field of economic growth and after a long list of empirical papers following the models derived from the growth theories developed in the early nineties, authors such as Ciccone and Jarocinski (2010) and Crespo-Cuaresma et al. (2014) have contrasted their validity/ robustness following Bayesian model uncertainty approaches. Similarly, Camarero et al. (2015) analyzed the determinants of the energy consumption - growth link, Camarero et al. (2019) used a similar strategy to analyze the determinants of foreign direct investment and Hortas-Rico and Rios (2019) focused on the drivers of income inequality. Bayesian methods have also been used in the banking field, although there are fewer contributions. For instance, Feng and Serletis (2010) measure banks' productivity and efficiency for large American banks. Assaf et al. (2011) analyze the productivity and efficiency of Japanese Shinkin banks [4], while Assaf et al. (2013) examine the productivity and efficiency of Turkish banks. Other authors such as Baele et al. (2015) analyze the driving factors of equity returns for US banks and Tsionas et al. (2018) examine for a panel of US commercial banks the relationship between firms' cost efficiency and market power. More recently, Delis et al. (2020) estimate a model of management practices as an unobserved input in a standard production function for all US banks. However, the use of Bayesian techniques in the evaluation of banks' net interest margins is, to the best of our knowledge, still non-existent.

As a second contribution, and after analyzing which determinants can be considered as good predictors of the net interest margin, the paper reports inference results for the model, which best explain our variable of interest. As it is common in Bayesian methods, inference is provided in terms of complete probability distributions, the so-called posterior densities, which are more informative than the point estimates from the frequentist analyses, based on the average impact and its statistical significance ( $\phi$-values), whose validity needs from the compliance of strong assumptions.

The analysis is carried out for a wide sample of 3,316 banks from the EU-15 countries for the period 2008-2014. The empirical exercise proceeds as follows. We first analyze which
Profitability in the banking industry 
AEA

28,83

determinants have power to explain disparities in the net interest margin via Bayesian variable selection. After that, we carry out a model selection by proposing different models including the variables selected in the first step together with different combinations of bank, country and time effects and provide Bayesian inference for the model with the best explanatory capacity. In particular, the computational challenges derived from this exercise are overcome by using integrated nested Laplace approximations (INLA). The results confirm that the variables postulated by the seminal model and the two analyzed expansions are good predictors of the net interest margin. However, results slightly differ when the model incorporates ad-hoc variables traditionally used by the previous literature. Regarding the inference part, our results are generally aligned to contributions using alternative methodological approaches, with very few exceptions. Nonetheless, our Bayesian approach based on posterior probabilities enables a more complete study of their impact.

The remainder of the paper is structured as follows. Section 2 explains the methodology. Section 3 describes the sample and defines in detail all the variables and their construction. Section 4 reports and discusses the results and, finally, Section 5 concludes.

\section{Methodology}

Before explaining in detail the methodology it is worth mentioning that the approach to variable selection adopted in this paper is related to the Bayesian model averaging (BMA) approach by Fernández et al. (2001). A recent review of the approach and its importance in the field of Econometrics can be found in Steel (2017). The idea behind this approach is to select the best model to describe a given output, among all the possible ones. Of course, there exist other variable selection methods. This is the case, for instance, of penalized regression methods (Bayesian or frequentist) such as Lasso (Tibshirani, 1996). However, these are not exactly variable selection methods but what is called model dimension reduction approaches, where the goal is to reduce the dimensionality of a model by shrinking some of the coefficients to zero.

\subsection{Bayesian variable selection}

Bayesian methods depart from the establishment of a likelihood function and a prior distribution, the latter reflecting the previous knowledge of the annalist about the unknown parameters. Then, the Bayes Theorem is used to update the prior knowledge. Formally, given an unknown parameter $\theta$ and the observed data $\mathcal{D}$, this process can be expressed as:

$$
\pi(\theta \mid \mathcal{D})=\frac{L_{\mathcal{D}}(\theta) \pi(\theta)}{m(\mathcal{D})}
$$

where $\pi(\theta)$ and $\pi(\theta \mid \mathcal{D})$ summarize the prior and posterior believes about $\theta$, respectively; $L_{D}(\theta)$ is the likelihood for $\theta$ given the data; finally, $m(\mathcal{D})$ is the integrated likelihood, expressed as:

$$
m(\mathcal{D})=\int_{\Theta} L_{\mathcal{D}}(\theta) \pi(\theta) d(\theta)
$$

In the particular problem of variable selection, the annalist considers a set of $p$ variables that are potentially related to the output of interest. Each possible subset of these variables represents a different model among all the potential candidates. The final objective is the analysis of the goodness of fit of a total of $2^{p}$ models to decide which is the model that best 
fits our data. Specifically, assuming that the response variable is normally distributed, each competing model $M_{i}$ for $i=0, \ldots, 2^{p}-1$ relates the response variable to a subset of $k_{i}$ covariates such as:

$$
\boldsymbol{y}=\alpha_{0} \boldsymbol{X}_{0}+\boldsymbol{X}_{i} \boldsymbol{\beta}_{i}+\boldsymbol{\varepsilon}, \quad \boldsymbol{\varepsilon} \sim \mathrm{N}_{n}\left(\boldsymbol{O}, \sigma^{2} \boldsymbol{I}\right)
$$

where $\boldsymbol{y}$ is the $n$ dimensional vector of observations for the response variable; $\boldsymbol{\varepsilon}$ is a white noise error; $X_{0}$ is a $n \times k_{0}$ design matrix of fixed covariates (present in all models) with associated vector of effects $\alpha_{0} ; X i$ is the $n \times k_{i}$ design matrix containing potential covariates with $\boldsymbol{\beta} i$ being the $k_{i}$ vector of effects. In case there are no fixed variables (as in our case), covariates in $X_{0}$ are usually a $n$ dimensional vector of ones and so $\alpha_{0}$ represents the intercept.

To perform model selection in this scenario using the Bayes' rule, we consider the unknown $\theta$ in expression (1) to represent the theory better explaining data across a potential set of them. In particular, for each model $M_{i}$, using the Bayes' rule:

$$
P\left(M_{i} \mid \mathcal{D}\right) \propto L_{\mathcal{D}}\left(M_{i}\right) P\left(M_{i}\right)
$$

where $P\left(M_{i}\right)$ reflects the prior knowledge about $M_{i}$ being the "true" model and:

$$
L_{\mathcal{D}}\left(M_{i}\right)=\int_{\Theta} L_{\mathcal{D}}\left(\boldsymbol{\alpha}_{0}, \boldsymbol{\beta}_{i}, \sigma\right) \pi_{i}\left(\boldsymbol{\alpha}_{0}, \boldsymbol{\beta}_{i}, \sigma\right) d\left(\boldsymbol{\alpha}_{0}, \boldsymbol{\beta}_{i}, \sigma\right) .
$$

Notice that $L_{D}\left(\boldsymbol{\alpha}_{0}, \boldsymbol{\beta}_{i}, \sigma\right)$ represents the likelihood under $M_{i}$ and we need to define prior distributions for the unknown parameters within each model $\pi_{i}\left(\boldsymbol{\alpha}_{0}, \sigma, \boldsymbol{\beta}_{i}\right)$ and $\pi_{0}\left(\boldsymbol{\alpha}_{0}, \sigma\right)$. Following this notation we refer to $\boldsymbol{\alpha}_{0}, \sigma$ as the common parameters, as they are present in every model and to $\boldsymbol{\beta}_{i}$ as the extra parameters, as they change across models.

Departing from this approach, we follow Camarero et al. (2015) to compute the posterior inclusion probability of each potential covariate, i.e. the probability of a covariate being in the "true" model after the data $\mathcal{D}$ are observed. Formally:

$$
p\left(x_{l} \mid \mathcal{D}\right)=\sum_{\left\{M_{i}: x_{l} \in M_{i}\right\}} P\left(M_{i} \mid \mathcal{D}\right), l=1,2, \ldots p
$$

As shown in Camarero et al. (2015), posterior probabilities of the entertained models $M_{i}$ can be calculated exactly departing from expression (4) as:

$$
P\left(M_{i} \mid \mathcal{D}\right)=\frac{B_{i 0} P\left(M_{i}\right)}{\sum_{j=0}^{2^{p}-1} B_{j 0} P\left(M_{j}\right)},
$$

where $B_{i 0}$ is a measure of the information contained in the data in favor of model $M_{i}$ and against the model $M_{0}$ (the one containing only the fixed covariates in $X_{0}$ ). This quantity is known as the Bayes Factor (Kass and Raftery, 1995) and it is calculated as the ratio of the integrated likelihood under each model:

$$
B_{i 0}=\frac{L_{\mathcal{D}}\left(M_{i}\right)}{L_{\mathcal{D}}\left(M_{0}\right)},
$$

where $L_{D}\left(M_{i}\right)$ is as in expression (5) for $i=0, \ldots, 2^{p}-1$. 
2.1.1 Prior over the model space $P\left(M_{i}\right)$. Scott and Berger (2010) show how these probabilities can serve as a multiplicity control tool, which is particularly needed in scenarios like variable selection, with huge model spaces. Indeed, Scott and Berger (2010) argue that it is important to account for the increasing number of models, and hence, for the difficulty of detecting influential covariates when $p$ and, presumably the background noise, grow.

As Scott and Berger (2010) point out, a standard practice in variable selection is to assign probability $q$ to each variable being in the model and consider their inclusion in a model as exchangeable Bernoulli trials. That is:

$$
P\left(M_{i} \mid q\right)=q^{k_{i}}(1-q)^{p-k_{i}}
$$

A fixed value of $q$ (independent of $p$ ) does not control for multiplicity. For instance, selecting $q=1 / 2$ gives the same results than giving an equal prior probability to each model. Scott and Berger (2010) show that treating $q$ as an unknown parameter and allowing learning from the data results in an automatic penalty for multiplicity. Choosing a uniform prior for $q$ in expression (8) and integrating it out results in:

$$
P\left(M_{l}\right)=\frac{1}{p+1}\left(\begin{array}{l}
p \\
k_{l}
\end{array}\right)^{-1} .
$$

It is worth mentioning that the prior distribution in expression (9) is equivalent to setting a uniform prior to each dimension $k$ (from 0 to $p$ ), that is $P(k)=1 /(p+1)$ for $k=0, \ldots, p$ and then dividing this probability equally among the $\left(\begin{array}{l}p \\ k\end{array}\right)$ models of dimension $k_{l}=k$. This proposal results in marginal prior inclusion probability of $1 / 2$ for each variable, the same as the one for the constant prior $P\left(M_{i}\right)$ but the behavior is very different because of the way of apportioning the probability among models.

2.1.2 Prior distribution for model-specific parameters. Prior distribution for modelspecific parameters are the most problematic element in this setting and the literature on this issue is extensive (Bayarri et al., 2012; Liang et al., 2008; Zellner and Siow, 1980, 1984; Zellner, 1986).

In particular, we consider the Jeffreys-Zellner-Siow approach, this is:

$$
\pi_{i}\left(\boldsymbol{\beta}_{0}, \boldsymbol{\beta}_{i}, \sigma\right)=\pi\left(\boldsymbol{\beta}_{0}, \sigma\right) \pi_{i}^{R}\left(\boldsymbol{\beta}_{i} \mid \boldsymbol{\beta}_{0}, \sigma\right)=\sigma^{-1} \times \int_{0}^{\infty} \mathrm{N}_{k_{i}}\left(\boldsymbol{\beta}_{i} \mid \mathbf{0}, g \Sigma_{i}\right) p_{i}(g) d g,
$$

where $\Sigma_{i}=\operatorname{Cov}\left(\hat{\boldsymbol{\beta}}_{i}\right)=\sigma^{2}\left(\boldsymbol{V}_{i}^{t} \boldsymbol{V}_{i}\right)^{-1}$ is the covariance of the maximum likelihood estimator of $\beta_{i}$ with:

$$
V_{i}=\left(\boldsymbol{I}_{n}-\boldsymbol{X}_{0}\left(\boldsymbol{X}_{0}^{t} \boldsymbol{X}_{0}\right)^{-1} \boldsymbol{X}_{0}^{t}\right) \boldsymbol{X}_{i}
$$

and $p_{i}(g)$ is a Cauchy distribution over the hyper parameter $g$.

To perform the analysis we consider the R-package $B A S$ (Clyde, 2018). In particular, we use the function bas.lm to obtain the posterior inclusion probabilities (PIPs) of the potential covariates [5]. 


\subsection{Bayesian inference using integrated nested Laplace approximations}

Regarding the computational challenges related to Bayesian inference, some of the most used solutions are Monte Carlo Markov Chain methods (MCMC) (Carlin and Louis, 2000) or the Laplace Integration, which is implemented in the INLA software (Wang et al., 2018), available in the software (R Core Team, 2019). We adopted the second alternative, as it offers several computation advantages in front of MCMC.

Apart from the effect of potential covariates, time and space can affect any process of interest. In particular, every bank can perform differently because of different business the banking industry strategies. Also, the economic situation can change with time affecting the level of the net interest margin. Finally, despite some regulatory aspects are common to all sample banks (Basel III), some aspects can be country-specific, thus being necessary to account for country effects too. To account for these effects, we can incorporate random effects to our linear models. Random effects are useful tools (as shown in Baltagi (2008)), which can reflect temporal or spatial structures in the data or just account for the independent performance of different banks or countries.

In particular, we consider three different random effects:

- A year effect $t=2008, \ldots, 2014$ defined as an order one random walk, and thus meaning that for each year the value of the effect is centered at the previous year:

$$
a_{t} \sim N\left(a_{t-1}, \sigma_{a}^{2}\right)
$$

with $a_{t}$ being the random effect of year $t$. It is important to highlight that this modeling of the year effect allows for incorporating the dynamics of the net interest margin considering that its residual value (after taking into account other relevant variables) may not be far from the one in the previous year.

- An independent random effect per bank $b_{i}$ for $i=1, \ldots, 3316$

$$
b_{i} \sim N\left(0, \sigma_{b}^{2}\right),
$$

accounting for an independently different base level of the net interest margin for each bank.

- An independent random effect per country $c_{i}$ for $i=1, \ldots, 15$

$$
c_{i} \sim N\left(0, \sigma_{c}^{2}\right),
$$

reflecting different base levels of the net interest margin in each country.

Considering all these random effects, the model to be estimated is:

$$
y=X^{*} \beta^{*}+A \boldsymbol{a}+B \boldsymbol{b}+C \boldsymbol{c}+\varepsilon,
$$

where $\boldsymbol{X}^{*}$ is the design matrix resulting from the variable selection step described in Section 2.1 with associated effects $\boldsymbol{\beta}^{*} ; \boldsymbol{A}$ is a $n \times 7$ design matrix with dummy variables indicating the year of each observation and $\boldsymbol{a}=\left(a_{1}, \ldots, a_{7}\right)$ is the vector of all the random effects associated to the seven years considered; equivalently $\boldsymbol{B}$, $\boldsymbol{C}$, indicate the bank and the country of each observed value in $\boldsymbol{y}$ and $\boldsymbol{b}$ and $\boldsymbol{c}$ their respective random effects. Finally $\boldsymbol{\varepsilon} \sim$ $\mathrm{N}_{n}\left(\boldsymbol{O}, \boldsymbol{\sigma}^{2} \boldsymbol{I}\right)$ represents a white noise measurement error. 
AEA 28,83

The inclusion of this type of effects usually produce a non tractable expression for $m(\mathcal{D})$, something that is solved by using INLA. It uses the Laplace approximation to the integral in $m(\mathcal{D})$, using Taylor's series expansions as shown in Rue et al. (2009) [6]. Specifically, we fit the $2^{3}=8$ resulting models from combining $a, b$ and $c$ with the selected covariates in the previous step. Then, the best model is selected using the Watanabe Akaike information criterion (WAIC) developed by Watanabe (2010). This information criterion takes into account posterior densities to provide a measure of the goodness of fit of the model. The lower the WAIC, the better the model (see, for the description of other information criteria, Gelman et al., 2014). For the model that best fits our statistical problem, we apply INLA to obtain summaries of the posterior distributions of the unknown parameters of interest. Then, we interpret the result in economic terms using this posterior inference.

\section{Empirical framework}

\subsection{Sample, data and sources}

The analysis is carried out using a sample of 3,316 banks from the EU-15 [7] countries for the period 2008-2014. This sample was selected based on two criteria. First, regarding the geographical component, the EU-15 is homogeneous in terms of monetary policy and banking regulation, centralized in the ECB. Second, concerning the temporal period, although the analysis cannot be extended beyond 2014 due to data availability problems, our period corresponds to the economic crisis years, when the banking industry faced the restructuring process, featured by more restrictive regulations that tightened the competitive conditions, which makes our analysis particularly interesting.

The source for the bank-specific characteristics is the Bureau Van Dijk's BankScope database, where all the monetary magnitudes are expressed in thousands of euros. We used consolidated financial statements when possible. This decision was made because the consolidated financial statements are more suitable to measure the overall position of the entity, as both parent and subsidiaries conform a single economic entity. In some cases, however, this information is not available and we were obliged to use unconsolidated information, which is a common practice in the literature in these cases. Interest rates data come from the OECD database [8]. We provide in the following section a detailed description of all the variables included.

\subsection{Variables description}

The dependent variable is the net interest margin per unit of asset, defined as the difference between revenue and financial costs in relation to total assets. This variable reflects the difference between the interest charged by banks to their clients for loans and the interest paid for their deposits. The variables used to explain net interest margins are those postulated by the seminal paper by Ho and Saunders (1981), together with those in some subsequent extensions and other variables included ad-hoc in most of the previous empirical studies. As commented in the introduction, we consider two of the most contrasted extensions of the seminal model so far, namely Angbazo (1997) and Maudos and Fernández de Guevara (2004). The seminal model by Ho and Saunders (1981) includes as explanatory variables market power, risk aversion, average size of banks' transactions and interest rate risk. The extension by Angbazo (1997) incorporates credit risk and the interaction between interest risk and default risk. The extension by Maudos and Fernández de Guevara (2004) adds to that framework the average operating costs. Finally, the implicit interest payments, management quality and liquid reserves are traditional ad-hoc variables. All these variables are explained in detail below. 
3.2.1 Ho and Saunders' (1981) baseline model

3.2.1.1 Market power (Lerner index). Market power is proxied by the Lerner index, estimated at the bank level as follows:

$$
\text { Lernerindex } x_{i}=\frac{P_{i}-C M_{i}}{P_{i}}
$$

where the price of the banking output $\left(P_{i}\right)$ is approximated by the ratio of total revenues to total assets. Total assets $\left(T A_{i}\right)$ are used as an indicator of banking activity following Maudos and Fernández de Guevara (2004) and Carbó et al. (2009), among others. The marginal cost $\left(C M_{i}\right)$ of banking production is calculated from the following translogarithmic cost function [9]:

$$
\begin{aligned}
\ln C_{i t}= & \alpha_{0}+\alpha_{1} \ln T A_{i t}+\frac{1}{2} \alpha_{k}\left(\ln T A_{i t}\right)^{2}+\sum_{j=1}^{3} \beta_{j} \ln w_{j i t} \\
& +\frac{1}{2} \sum_{j=1}^{3} \sum_{k=1}^{3} \beta_{j k} \ln _{j i t} \ln _{k i t}+\frac{1}{2} \sum_{j=1}^{3} \gamma_{j} \ln T A_{i t} \ln _{j i t}+\mu_{1} \text { Trend } \\
& +\frac{1}{2} \mu_{2} \text { Trend }^{2}+\mu_{3} \operatorname{Trend}_{\ln T A_{i t}}+\sum_{j=1}^{3} \delta_{j} \operatorname{Trend}_{\ln w_{i j t}+\nu_{i}+u_{i t}}
\end{aligned}
$$

where $C$ stands for total costs (both financial and operating costs) and $w$ are the prices of the three inputs, measured as follows:

$$
\begin{aligned}
& w_{1}: \text { Price of labor }=\text { staff costs } / \text { total assets } \\
& w_{2}: \text { Price of capital }=\text { operating costs }(\text { except staff costs }) / \text { fixed assets } \\
& w_{3}: \text { Price of deposits = financial costs } / \text { deposits }
\end{aligned}
$$

As indicated by Koetter et al. (2012), the conventional approach to compute the Lerner index assumes perfect technical and allocative efficiency. However, operating costs and efficiency may vary depending on the economic environment in which banks operate (Chaffai et al., 2001) and also over time. As banks are expected to adapt internally to these changing conditions, the cost function is estimated including bank fixed effects $(\nu)$. In addition, a trend (Trend) is included to capture the technical change over time. The Lerner index ranges between zero and one. The higher the index the greater the market power. The expected sign is positive, given that increased market power allows for setting larger interest margins.

3.2.1.2 Risk aversion. The degree of risk aversion is measured following the McShane and Sharpe's (1985) approach, defined as the ratio between the total equity of the bank and its total assets. The expected sign is positive, as more risk averse banks set higher margins [10].

3.2.1.3 Size. The logarithm of the total assets is used as a proxy for the size of bank operations. The expected sign of this variable, according to the theoretical model, is positive. Larger banks can be perceived by their clients as less risky because they are too big to fail, being able to accept lower interest rates on their deposits and, therefore, margins can be greater for large banks.

3.2.1.4 Interest rate risk. Interest rate risk is usually proxied by the volatility of a representative interest rate in the money market. In particular, we use the coefficient of
Profitability in the banking industry 
AEA 28,83

variation of the three-month interbank interest rate, calculated with monthly data. We consider the coefficient of variation as a better proxy than the standard deviation, as it collects not only the volatility but also the level of the interest rates. The expected sign of the relationship between this variable and the net interest margin is positive, given that greater volatility implies greater risk and, therefore, the bank will set a higher margin in the attempt to compensate that risk.

3.2.2 Extension by Angbazo (1997)

3.2.2.1 Credit risk. The default risk obliges banks to include an implicit risk premium in the interest rates that they charge for their operations. As a proxy for this risk we use the ratio between provisions and the volume of credit granted. The expected sign of this variable is positive, as the higher the default risk the higher the provisions made by the bank.

3.2.2.2 Risk interaction. Interaction between credit risk and interest rate risk, computed as the product of the variables that approximate the two risks.

3.2.3 Extension by Maudos and Fernández de Guevara (2004)

3.2.3.1 Average operating costs. This variable is proxied by the ratio between total operating costs and total assets. As the net interest margin should cover, at least, the operating costs, the expected sign is positive, as the model predicts that banks transfer higher costs to the final clients through increased margins.

\subsubsection{Ad-hoc determinants}

3.2.4.1 Reserves. The liquid reserves maintained by a bank are approximated by the ratio between these reserves and the total assets. As the maintenance of liquid reserves supposes an opportunity cost for the bank by refusing to invest in more profitable assets, the expected sign of this variable will depend on whether the bank is able to transfer this opportunity cost to its clients (positive sign) or not (negative sign). Moreover, reserves represent a source of balance sheet stability.

3.2.4.2 Implicit payments. Banks, in addition to pay an interest rate for their deposits, may offer other services associated with them for which sometimes obtain an implicit remuneration (paying a lower interest rate) rather than explicit remuneration (charging a fee for the service provided). Following the previous literature, to proxy this variable we use the operating expenses net of non-interest revenues as a percentage of total assets. The expected relationship between this variable and net interest margin is positive, as higher implicit interest payments imply higher operating costs, which have to be compensated setting a greater net interest margin.

3.2.4.3 Efficiency. The efficient management of a bank implies the choice of the most profitable assets and the deposits with the lowest costs. To proxy this variable the ratio between operating expenses and ordinary margin is used. The lower the ratio, the more efficient the bank is. Therefore, the expected sign of this variable is negative, as more efficient banks enjoy higher net interest margins.

\subsection{Descriptive statistics}

Figure 1 shows both the level and the evolution of the net interest margin weighted by total assets over the analyzed period. A decline is observed between 2008 and 2012, followed by a faster recovery in the past two years analyzed [11]. For the rest of variables included in the analysis, Table I reports some descriptive statistics.

Figure 2 displays a correlation matrix. Considering bilateral correlations between the net interest margin and the potential explanatory variables, we observe positive correlations with market power (Lerner index), risk aversion, credit risk, average costs, implicit payments and reserves. In contrast, size shows a negative correlation with the dependent variable. The 


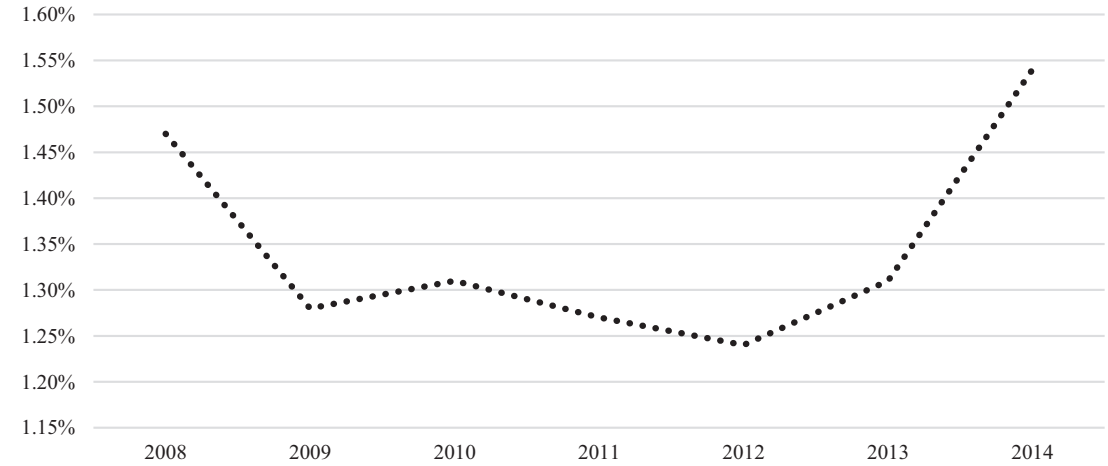

Note: The graph shows the evolution of the net interest margin weighted by total assets
Profitability in the banking industry

Figure 1.

Evolution of the net interest margin 2008-

2014

\begin{tabular}{llrrrrrr}
\hline & & & & \multicolumn{2}{c}{$\begin{array}{c}\text { First } \\
\text { quartile }\end{array}$} & $\begin{array}{c}\text { Median } \\
\text { Variable }\end{array}$ & Description
\end{tabular}

Note: The source for the bank-specific characteristics is the Bureau Van Dijk's BankScope database, where all the monetary magnitudes are expressed in thousands of euros

Table I.

Descriptive statistics

variables efficiency and interest rate risk have a weak correlation with our variable of interest.

\section{Results}

This section summarizes the results of the application of the Bayesian techniques explained in the methodological section. We first evaluate, which of the potential determinants of the net interest margin are actually good predictors. To that end, we consider four scenarios. The first includes only the seminal Ho and Saunders' (1981) variables; the second adds the variables of the extension by Angbazo (1997); the third incorporates the variables of the 
AEA

28,83

122

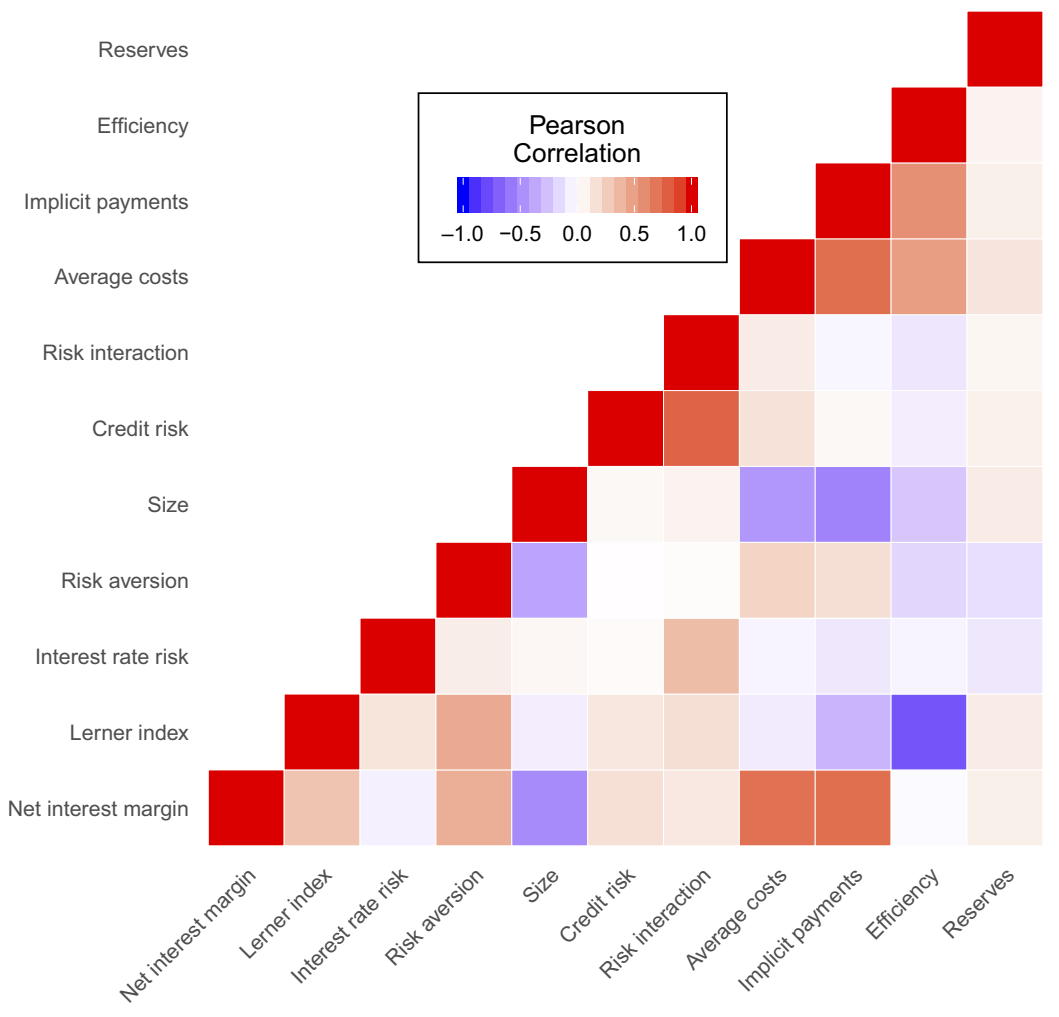

Notes: The matrix summarizes the relationship among all the variables of the analysis. Higher color intensity is associated to a higher correlation
Figure 2.

Correlation matrix

Maudos and Fernández de Guevara's (2004) extension; and the fourth adds variables not included in the theoretical models but commonly used by the previous literature. As commented in the introduction, this last scenario is a common framework in the specialized literature. In a second step, we consider different models including the variables that survived the first step - i.e. the robust determinants, combined with different effects (bank level, country level and year) and assess their explanatory capacity. Finally, we provide inference results for the parameters of the model with the best fit.

\subsection{Selection of the determinants of bank net interest margin}

Table II reports the results for the variable selection. The first column suggests that all the variables of the seminal model by Ho and Saunders (1981) have an inclusion probability equal to 1. This result provides strong support on the adequacy of Ho and Saunders' (1981) determinants to explain net interest margin disparities. When assessing the first expansion by Angbazo (1997) (second column), we observe that all of the variables are included with inclusion probabilities of 1 , except for the case of risk interaction, for which the inclusion probability is slightly lower (0.693). The third column shows the results when the variable average costs is included following Maudos and Fernández de Guevara (2004). In this case, 


\begin{tabular}{|c|c|c|c|c|c|}
\hline Variable & Seminal model & Extension (I) & Extension (II) & Ad-hoc variables & lity in \\
\hline Lerner index & 1.000 & 1.000 & 1.000 & 1.000 & . 1 \\
\hline Risk aversion & 1.000 & 1.000 & 1.000 & 1.000 & \\
\hline Size & 1.000 & 1.000 & 1.000 & 0.164 & \\
\hline Interest rate risk & 1.000 & 1.000 & 1.000 & 1.000 & \\
\hline Credit risk & - & 1.000 & 0.988 & 0.086 & \\
\hline Risk interaction & - & 0.693 & 0.198 & 1.000 & 12 \\
\hline Average costs & - & - & 1.000 & 1.000 & \\
\hline Implicit payments & - & - & - & 1.000 & \\
\hline Efficiency & - & - & - & 1.000 & \\
\hline Reserves & - & - & - & 1.000 & Table I \\
\hline \multicolumn{5}{|c|}{$\begin{array}{l}\text { Notes: The table reports the results for the variable selection. The seminal model is the model of Ho and } \\
\text { Saunders (1981), the Extension (I) corresponds to the extension by Angbazo (1997) and the Extension (II) is } \\
\text { that by Maudos and Fernández de Guevara (2004). PIPs above 0.5 indicate high probability of inclusion }\end{array}$} & $\begin{array}{l}\text { PIPs for the net } \\
\text { interest margin } \\
\text { determinants }\end{array}$ \\
\hline
\end{tabular}

all the variables have a high probability of inclusion, with the exception of risk interaction, whose probability of inclusion is only 0.198 . Finally, regarding the most comprehensive model, which includes also other variables commonly used in the empirical literature, the variables size and credit risk have very low probabilities of inclusion. However, the result for the latter variable is fully determined by the inclusion of risk interaction. Given that the results suggest that it should be included in the model, we decided to maintain also credit risk to better interpret the interaction effect. Therefore, the only variable excluded from this more comprehensive model is size. A potential explanation is that the variable is highly correlated with other variables in the model, especially with implicit payments (negative correlation) and therefore the effect of size can be captured by this latter variable. The rest of results suggest that the seminal model by Ho and Saunders (1981) and its extensions analyzed in this study (Angbazo, 1997 and Maudos and Fernández de Guevara, 2004) are validated in a framework of model uncertainty and using Bayesian variable selection.

Departing from the most comprehensive scenario (fourth column of Table II), alternative specifications are formulated including different combinations of individual bank, country and time effects. As mentioned in Section 2, to select our baseline specification for which inference will be provided we rely on the WAIC, obtained using INLA and summarized in Table III. Considering that the lower the WAIC, the better the model, we choose Model 8 which includes, in addition to the variables considered in the variable selection, independent effects for bank and country as well as an order one autoregressive, AR(1), year effect.

\subsection{Inference for the determinants of bank net interest margin}

As it is common when applying Bayesian methods, inference results are provided in terms of posterior probability distributions of the estimated model parameters. Table IV reports the summary of the distributions for all the variables in Model 8 obtained using INLA, whereas Figure 3 displays the graphical counterparts.

Regarding the variables from the seminal model by Ho and Saunders (1981), the market power (Lerner index), shows a positive impact (associated average regression parameter $\beta$ $=0.0177$ ), as the theoretical model predicts. Its standard deviation is remarkably small, indicating that the estimated effect is relatively accurate. This result implies that banks with more market power set higher interest margins. The result is consistent with that obtained by Maudos and Fernández de Guevara (2004) for the main European banking sectors, 


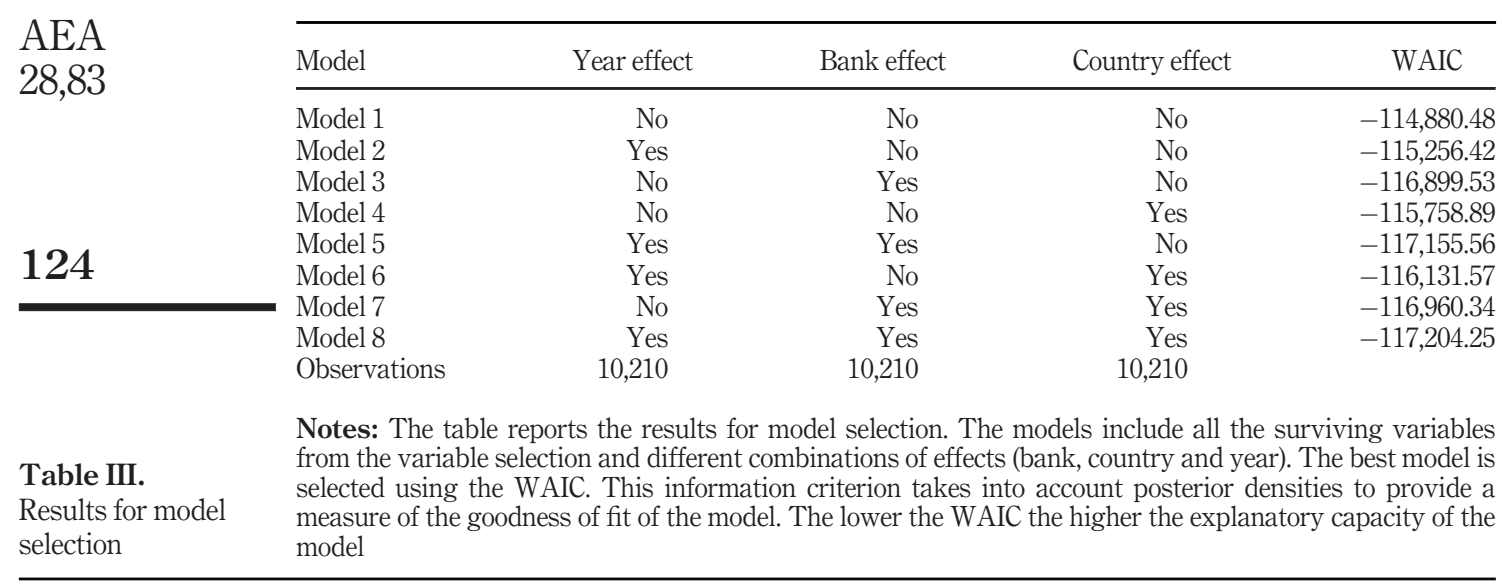

\section{Table IV.}

Posterior probabilities for variables included in the selected model (Model 8)

\begin{tabular}{lrrrrr}
\hline Variable & Mean & Sd & Q 0.025 & Median & Q 0.975 \\
\hline Intercept & 0.0150 & 0.0009 & 0.0131 & 0.0150 & 0.0168 \\
Lerner index & 0.0177 & 0.0007 & 0.0162 & 0.0177 & 0.0192 \\
Risk aversion & 0.0080 & 0.0011 & 0.0059 & 0.0080 & 0.0101 \\
Interest rate risk & -0.0020 & 0.0004 & -0.0027 & -0.0020 & -0.0012 \\
Credit risk & 0.0120 & 0.0047 & 0.0028 & 0.0120 & 0.0212 \\
Risk interaction & 0.0351 & 0.0150 & 0.0058 & 0.0351 & 0.0645 \\
Average costs & 0.3792 & 0.0081 & 0.3632 & 0.3792 & 0.3952 \\
Implicit payments & 0.8759 & 0.0091 & 0.8580 & 0.8759 & 0.8937 \\
Efficiency & -0.0249 & 0.0005 & -0.0259 & -0.0249 & -0.0238 \\
Reserves & -0.0087 & 0.0019 & -0.0125 & -0.0087 & -0.0049
\end{tabular}

Notes: The table reports the summary of the posterior distributions for all the selected variables in Model 8 obtained using INLA. Model 8 includes bank, country and year effects. Q 0.025 and Q 0.975 refer to quantiles 2.5 and 97.5 of the posterior distribution of the variables, respectively

Cruz-García and Fernández de Guevara (2020) for OCDE countries and Angori et al. (2019) for the euro area, etc. The variable risk aversion has also a positive impact $(\beta=0.008)$, suggesting that more risk averse banks set higher interest margins. In both cases, the entire probability distribution is positive. The result is in line with Maudos and Fernández de Guevara (2004) for European banks and Maudos and Solís (2009) for the Mexican banking sector. However, interest rate risk has a negative effect on the net interest margin, which is against the theoretical model predictions.

The regression coefficients for credit risk and the risk interaction (variables included in the Angbazo's, 1997 extension) have the predicted positive sign. This indicates that the banks with higher credit risk set higher interest margins, as they include a risk premium. The average costs, added in the expansion by Maudos and Fernández de Guevara (2004) also have the expected positive effect, suggesting that banks bearing higher operating expenses need to set higher margins to cover them. These results are also in line with Maudos and Fernández de Guevara (2004) and Cruz-García and Fernández de Guevara (2020). 

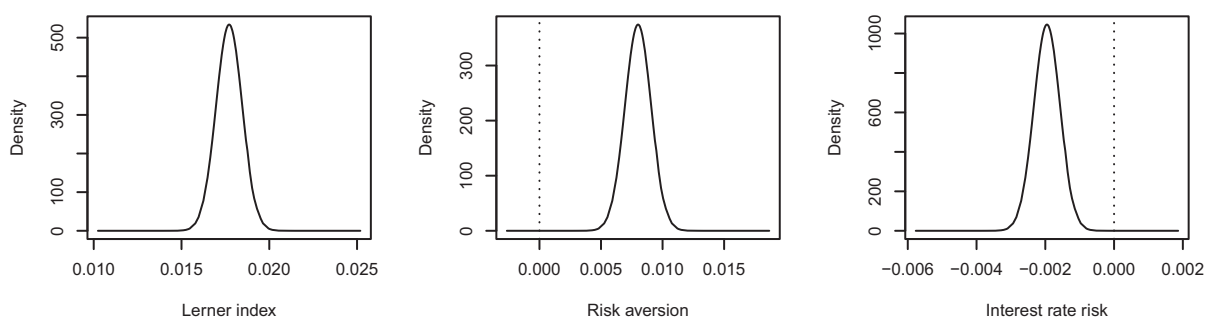

Profitability in the banking industry
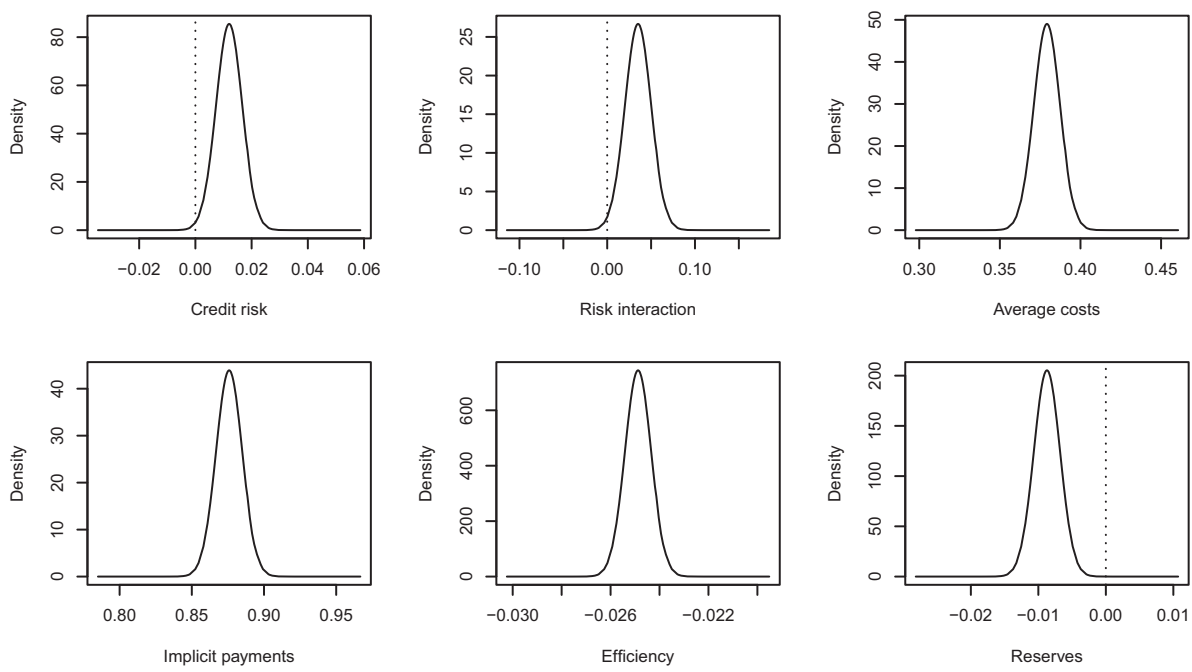

Notes: The figure displays the distributions for all the estimated effects in Model 8 obtained using INLA. For each variable, the distribution summarizes the estimated impact of that variable on net interest margin in probabilistic terms, assuming that the rest of variables remain constant. The dotted vertical line set at zero helps to distinguish positive and negative effects

Figure 3.

Posterior distributions of the determinants of net interest margin

Finally, with respect to the variables included ad-hoc, the implicit payments have a notable positive impact on the net interest margin, while efficiency and reserves show a negative one. These results imply that higher implicit payments translate into a greater margin, as they imply a greater cost that the bank should cover. Also, it means that banks cannot translate the opportunity cost of maintaining higher liquid reserves to their clients. Finally, the results also suggest that more efficient banks (better managed) enjoy larger margins (remember that the lower the variable the more efficient the bank is). The results for the ad-hoc variables are also in line with those obtained by Cruz-García and Fernández de Guevara (2020) [12].

To better quantify the impact of the determinants of net interest margin, Figure 4 shows the estimated change in that variable associated with variations from percentile 2.5 to percentile 97.5 of each explanatory variable. To do that, we take the posterior mean of the associated effect and multiply it by the variation of the specific variable. The largest impacts are found for implicit payments (positive) and efficiency (negative), with median estimated effects of 0.017 and -0.017 , respectively. Other variables with relative large impacts are 
AEA

28,83

126

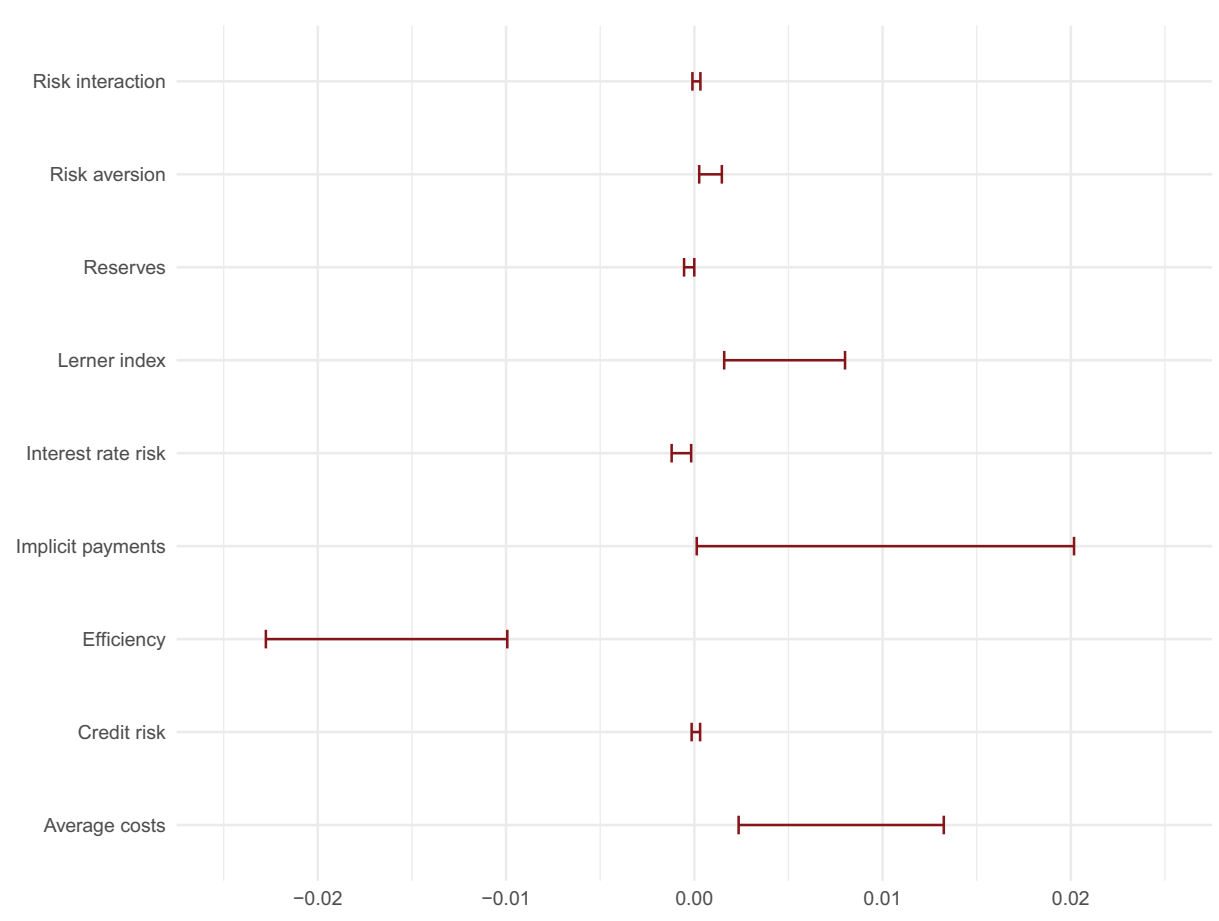

Figure 4.

Economic impact of the determinants on net interest margin

Note: The graph shows the effect on net interest margin of a variation from percentile 2.5 to percentile 97.5 of the distribution in each of the explanatory variables

average costs $(0.007)$ followed by the Lerner index (0.004). The remaining variables have more modest impacts.

\section{Conclusions}

This paper has analyzed the potential determinants of the main source of banks' profitability, the net interest margin. The literature dealing with this issue is abundant, although there is still room for contributions such as that by this paper, which comes mainly from the methodological side. In particular, we provide fresh evidence following a Bayesian perspective, which is novel in this context. We first analyze, which variables of those proposed by the literature can be considered as robust determinants of the net interest margin. Then, we apply INLA to overcome well-known operational challenges, select the model with the best fit and provide Bayesian inference. One of the most interesting features of our approach is that for each regressor we are able to provide the complete probability distribution for its associated parameter, which is more informative than the punctual estimates yielded by the more common frequentist approaches relying on $p$-values.

The analysis is carried out for a large sample of 3,316 EU-15 banks for the period 20082014. The candidate variables have been those postulated by the seminal theoretical model by Ho and Saunders (1981), together with subsequent extensions by Angbazo (1997) and Maudos and Fernández de Guevara (2004), which are the most adopted frameworks in the 
related literature. In addition, we considered other variables traditionally included in the empirical analyses, even though they are not theoretically-grounded.

The results from the variable selection show that the seminal model and the two expansions considered are successful in explaining net interest margin variations. However, when other ad-hoc variables are included, we find that the bank size becomes a weak predictor and should not be included as a determinant. Following the WAIC criterion for evaluating the adjustment of a set of alternative models, we found that the model that includes the variables indicated by the variable selection, together with effects for bank, country and year is the one offering the best fit. Inference for that specification generally confirms the predictions of the theoretical models, with the only exception of the interest rate risk, for which we find a negative impact.

According to our results, banks with greater market power, more risk averse, with a higher credit risk, which bear higher operating costs, having higher implicit payments and being more efficient, enjoy larger net interest margins, enhancing their profitability. However, banks with a higher volume of liquid reserves and with a higher interest rate risk have a more reduced interest margin. Despite the abovementioned subtleties, the results generally confirm the theoretical predictions.

Our results are interesting for several reasons. On the one hand, they are obtained using a different methodology, which became more common in other branches of the economic literature in the last years but it is novel in our particular context. Dealing with variable and model uncertainty have allowed to corroborate that the seminal theoretical models offer a good performance and are indeed useful to explain disparities in banks' profitability. On the other hand, the period analyzed is particularly relevant, as the banking environment has become more challenging.

Due to the crisis, bank regulations tightened, with greater capital requirements, new liquidity and leverage coefficients, among other measures. At the same time, the main central banks have carried out an expansionary monetary policy that lowered interest rates. In addition, the competitive conditions in the banking sector have also changed. The need for bank restructuring has led to multiple mergers and acquisitions, thus, increasing banking concentration, which may be detrimental to competition. Simultaneously, the progress toward the banking union has also resulted in a more competitive scenario. Finally, new technologies are also increasing competition in the financial sector with the emergence of the fintech and big tech firms. Despite this new competitive environment, our results highlight that the traditional determinants of banks' earnings still matter.

Our findings can be expanded in several angles. For instance, it would be interesting to expand the analysis, especially once the European banking union is fully completed. Also, a better understanding of the mechanisms and mediators behind the relationships observed is needed, as for instance, jointness analyses or analyses exploring parameter heterogeneity and nonlinearities. These are only some of the issues that would benefit from specific attention in future contributions.

\section{Notes}

1. Non-traditional activities are those other than the granting of loans and the acceptance of deposits.

2. Zarruk (1989), Zarruk and Madura (1992) and Wong (1997), among others.

3. Other extensions were not included in our analysis because they do not follow the sequence of models departing from Ho and Saunders (1981) to Maudos and Fernández de Guevara (2004).
Profitability in the banking industry 
AEA 28,83
4. In Japan, these are cooperative regional financial institutions serving small and medium enterprises and local residents.

5. Other R packages for doing Bayesian variable selection can be found in Forte et al. (2017).

6. Additional technical details on this approach are beyond the scope of this paper and we instead refer the interested reader to Blangiardo and Cameletti (2019) or Wang et al. (2018) for a full description and tutorials on its usage.

7. Austria, Belgium, Germany, Denmark, Spain, Finland, France, United Kingdom, Greece, Ireland, Italy, Luxembourg, The Netherlands, Portugal and Sweden.

8. https://data.oecd.org/interest/short-term-interest-rates.htm

9. In line with the literature, we impose symmetry restrictions and homogeneity of degree one in input prices.

10. This variable should be interpreted cautiously, as it incorporates the total capitalization of the bank, including the capital requirements (which are mandatory) and may not reflect the capital that the bank voluntarily maintains.

11. Keep in mind that, although the net interest margin of the new operations declined, the variable includes the income and expenses of all outstanding loans and deposits. This implies that it is an average indicator of the net interest margin of the new operations and the loans/deposits granted/ received in previous years.

12. Some authors such as Dietrich and Wanzenried (2014) have used alternative measures of bank profitability such as the return on assets (ROA) or the return on equity (ROE). We avoided testing our models using these variables, given that the theoretical models that we consider in this paper are specifically addressed to explain the net interest margin and not other measures of bank profitability. However, we do follow Saona (2016), who proposed an alternative measure of net interest margin, which is computed as the net interest revenue over total earning assets instead of net interest revenue over total assets (our original variable). As a robustness check, we repeated the whole empirical exercise using this alternative definition of the dependent variable and the results remain virtually invariant. For space reasons, these results are not included in the paper but they can be provided upon request.

\section{References}

Allen, L. (1988), "The determinants of bank interest margins: a note", The Journal of Financial and Quantitative Analysis, Vol. 23 No. 2, pp. 231-235.

Amuakwa-Mensah, F. and Marbuah, G. (2015), "The determinants of net interest margin in the Ghanaian banking industry", Journal of African Business, Vol. 16 No. 3, pp. 272-288.

Angbazo, L. (1997), "Commercial bank net interest margins, default risk, interest-rate risk, and offbalance sheet banking", Journal of Banking and Finance, Vol. 21 No. 1, pp. 55-87.

Angori, G., Aristei, D. and Gallo, M. (2019), "Determinants of banks' net interest margin: evidence from the Euro area during the crisis and post-crisis period”, Sustainability, Vol. 11 No. 14, pp. 37-85.

Assaf, A.G., Barros, C.P. and Matousek, R. (2011), "Productivity and efficiency analysis of Shinking banks: evidence from bootstrap and Bayesian approaches", Journal of Banking and Finance, Vol. 35 No. 2, pp. 331-342.

Assaf, A.G., Matousek, R. and Tsionas, E.G. (2013), “Turkish bank efficiency: Bayesian estimation with undesirable outputs", Journal of Banking and Finance, Vol. 37 No. 2, pp. 506-517.

Baele, L., De Bruyckere, V., De Jonghe, O. and Vander Vennet, R. (2015), "Model uncertainty and systematic risk in US banking", Journal of Banking and Finance, Vol. 53, pp. 49-66.

Baltagi, B.H. (2008), Econometric Analysis of Panel Data, 4th ed., Wiley, New York, NY. 
Bayarri, M., Berger, J., Forte, A. and García-Donato, G. (2012), "Criteria for Bayesian model choice with application to variable selection", The Annals of Statistics, Vol. 40 No. 3, pp. 1550-1577.

Birchwood, A., Brei, M. and Noel, D.M. (2017), "Interest margins and bank regulation in Central America and the Caribbean", Journal of Banking and Finance, Vol. 85, pp. 56-68.

Blangiardo, M. and Cameletti, M. (2019), Spatial and Spatio-Temporal Bayesian Models with R-INLA, Wiley.

Borio, C., Gambacorta, L. and Hofmann, B. (2017), "The influence of monetary policy on bank profitability", International Finance, Vol. 20 No. 1, pp. 48-63.

Bustos-Contell, E., Climent-Serrano, S. and Labatut-Serer, G. (2019), "Changes in determinants of the interest margin in today's economy”, Economic Research-Ekonomska Istraživanja, forthcoming.

Camarero, M., Montolio, L. and Tamarit, C. (2019), "What drives German foreign direct investment? New evidence using Bayesian statistical techniques”, Economic Modelling, Vol. 83, pp. 326-345.

Camarero, M., Forte, A., García-Donato, G., Mendoza, Y. and Ordoñez, J. (2015), "Variable selection in the analysis of energy consumption-growth nexus", Energy Economics, Vol. 52, pp. 207-216.

Carbó, S. and Rodríguez, F. (2007), "The determinants of bank margins in European banking”, Journal of Banking and Finance, Vol. 31 No. 7, pp. 2043-2063.

Carbó, S., Rodríguez, F. and Udell, G. (2009), "Bank market power and SME financing constraints", Review of Finance, Vol. 13 No. 2, pp. 309-340.

Carlin, B.P. and Louis, T.A. (2000), Bayes and Empirical Bayes Methods for Data Analysis, 2nd ed., Chapman and Hall, London.

Chaffai, M.E., Dietsch, M. and Lozano-Vivas, A. (2001), “Technological and environmental differences in the European banking industries", Journal of Financial Services Research, Vol. 19 Nos 2/3, pp. 147-162.

Ciccone, A. and Jarocinski, M. (2010), "Determinants of economic growth: will data tell?", American Economic Journal: Macroeconomics, Vol. 2 No. 4, pp. 222-246.

Claeys, S. and Vander Vennet, R. (2008), "Determinants of bank interest margins in Central and Eastern Europe: a comparison with the West", Economic Systems, Vol. 32 No. 2, pp. 197-216.

Clyde, M. (2018), "BAS: Bayesian variable selection and model averaging using Bayesian adaptive sampling", R package version 1.5.3.

Crespo-Cuaresma, J.C., Doppelhofer, G. and Feldkircher, M. (2014), “The determinants of economic growth in European regions", Regional Studies, Vol. 48 No. 1, pp. 44-67.

Cruz-García, P. and Fernández de Guevara, J. (2020), "Determinants of net interest margin: the effect of capital requirements and deposit insurance scheme", The European Journal of Finance, Vol. 26 No. 11, pp. 1102-1123.

Delis, M.D., Iosifidi, M. and Tsionas, M. (2020), "Management estimation in banking”, European Journal of Operational Research, Vol. 284 No. 1, pp. 355-372.

Dietrich, A. and Wanzenried, G. (2014), "The determinants of commercial banking profitability in lowmiddle-and high-income countries", The Quarterly Review of Economics and Finance, Vol. 54 No. 3, pp. 337-354.

Doliente, J.S. (2005), "Determinants of bank net interest margins in Southeast Asia”, Applied Financial Economics Letters, Vol. 1 No. 1, pp. 53-57.

Entrop, O., Memmel, C., Ruprecht, B. and Wilkens, M. (2015), "Determinants of bank interest margins: Impact of maturity transformation", Journal of Banking and Finance, Vol. 54, pp. 1-19.

Feng, G. and Serletis, A. (2010), "Efficiency, technical change, and returns to scale in large US banks: panel data evidence from an output distance function satisfying theoretical regularity", Journal of Banking and Finance, Vol. 34 No. 1, pp. 127-138.

Fernández de Guevara, J. (2004), "Evolución del margen de intermediación en España: ? tipos de interés, riesgo, costes o competencia?", Revista de Economía Financiera, Vol. 2, pp. 4-27.

Profitability in the banking industry 
Fernández, C., Ley, E. and Steel, M.F. (2001), "Benchmark priors for Bayesian model averaging", Journal of Econometrics, Vol. 100 No. 2, pp. 381-427.

Forte, A., García-Donato, G. and Steel, M.F. (2017), "Methods and tools for Bayesian variable selection and model averaging in univariate linear regression", Technical report, arXiv:1612.02357v1 [stat.CO].

Gelman, A., Hwang, J. and Vehtari, A. (2014), "Understanding predictive information criteria for Bayesian models”, Statistics and Computing, Vol. 24 No. 6, pp. 997-1016.

Ho, T.S. and Saunders, A. (1981), "The determinants of bank interest margins: theory and empirical evidence", The Journal of Financial and Quantitative Analysis, Vol. 16 No. 4, pp. 581-600.

Hortas-Rico, M. and Rios, V. (2019), "The drivers of local income inequality: a spatial Bayesian modelaveraging approach”, Regional Studies, Vol. 53 No. 8, pp. 1207-1220.

Kannan, R., Narain, A. and Ghosh, S. (2001), "Determinants of net interest margin under regulatory requirements: an econometric study", Economic and Political Weekly, pp. 337-344.

Kass, R.E. and Raftery, A.E. (1995), "Bayes factors", Journal of the American Statistical Association, Vol. 90 No. 430, pp. 773-795.

Koetter, M., Kolari, J.W. and Spierdijk, L. (2012), "Enjoying the quiet life under deregulation? Evidence from adjusted Lerner indices for US banks", Review of Economics and Statistics, Vol. 94 No. 2, pp. $462-480$.

Lepetit, L., Nys, E., Rous, P. and Tarazi, A. (2008), “The expansion of services in European banking: implications for loan pricing and interest margins", Journal of Banking and Finance, Vol. 32 No. 11, pp. 2325-2335.

Liang, F., Paulo, R., Molina, G., Clyde, M.A. and Berger, J.O. (2008), "Mixtures of g priors for Bayesian variable selection", Journal of the American Statistical Association, Vol. 103 No. 481, pp. 410-423.

Liebeg, D. and Schwaiger, M. (2006), "Determinants of the interest rate margins of Austrian banks", Financial Stability Report, Vol. 12, pp. 104-116.

Lin, J.-R., Chung, H., Hsieh, M.-H. and Wu, S. (2012), "The determinants of interest margins and their effect on bank diversification: evidence from Asian banks", Journal of Financial Stability, Vol. 8 No. 2, pp. 96-106.

McShane, R. and Sharpe, I.G. (1985), "A time series/cross section analysis of the determinants of Australian trading bank loan/deposit interest margins: 1962-1981", Journal of Banking and Finance, Vol. 9 No. 1, pp. 115-136.

Maudos, J. and Fernández de Guevara, J. (2004), "Factors explaining the interest margin in the banking sectors of the European Union", Journal of Banking and Finance, Vol. 28 No. 9, pp. 2259-2281.

Maudos, J. and Solís, L. (2009), "The determinants of net interest income in the Mexican banking system: an integrated model", Journal of Banking and Finance, Vol. 33 No. 10, pp. 1920-1931.

Nguyen, J. (2012), “The relationship between net interest margin and noninterest income using a system estimation approach", Journal of Banking and Finance, Vol. 36 No. 9, pp. 2429-2437.

R Core Team (2019), R: A Language and Environment for Statistical Computing, R Foundation for Statistical Computing, Vienna.

Rue, H., Martino, S. and Chopin, N. (2009), “Approximate Bayesian inference for latent Gaussian models by using integrated nested Laplace approximations", Journal of the Royal Statistical Society: Series B (Statistical Methodology)), Vol. 71 No. 2, pp. 319-392.

Saad, W. and El-Moussawi, C. (2012), "The determinants of net interest margins of commercial banks in Lebanon", Journal of Money, Investment and Banking, Vol. 23, pp. 118-132.

Saona, P. (2016), "Intra-and extra-bank determinants of Latin American banks' profitability", International Review of Economics and Finance, Vol. 45, pp. 197-214.

Scott, J.G. and Berger, J.O. (2010), "Bayes and empirical-Bayes multiplicity adjustment in the variableselection problem", The Annals of Statistics, Vol. 38 No. 5, pp. 2587-2619. 
Steel, M.F.J. (2017), "Model averaging and its use in economics", MPRA Paper 81568, University Library of Munich.

Tibshirani, R. (1996), "Regression shrinkage and selection via the lasso", Journal of the Royal Statistical Society: Series B (Methodological)), Vol. 58 No. 1, pp. 267-288.

Tsionas, E.G., Malikov, E. and Kumbhakar, S.C. (2018), "An internally consistent approach to the estimation of market power and cost efficiency with an application to US banking”, European Journal of Operational Research, Vol. 270 No. 2, pp. 747-760.

Wang, X., Yue, Y.R. and Faraway, J.J. (2018), Bayesian Regression Modeling with INLA, CRC Press, Taylor and Francis.

Watanabe, S. (2010), "Asymptotic equivalence of Bayes cross validation and widely applicable information criterion in singular learning theory", Journal of Machine Learning Research, Vol. 11, pp. 3571-3594.

Williams, B. (2007), "Factors determining net interest margins in Australia: domestic and foreign banks", Financial Markets, Institutions and Instruments, Vol. 16 No. 3, pp. 145-165.

Wong, K.P. (1997), "On the determinants of bank interest margins under credit and interest rate risks", Journal of Banking and Finance, Vol. 21 No. 2, pp. 251-271.

Zarruk, E.R. (1989), "Bank spread with uncertain deposit level and risk aversion”, Journal of Banking and Finance, Vol. 13 No. 6, pp. 797-810.

Zarruk, E.R. and Madura, J. (1992), "Optimal bank interest margin under capital regulation and deposit insurance”, The Journal of Financial and Quantitative Analysis, Vol. 27 No. 1, pp. 143-149.

Zellner, A. (1986), "On assessing prior distributions and Bayesian regression analysis with g-prior distributions", in Zellner, A. (Ed.), Bayesian Inference and Decision Techniques: Essays in Honor of Bruno de Finetti, Edward Elgar Publishing, pp. 389-399.

Zellner, A. and Siow, A. (1980), "Posterior odds ratio for selected regression hypotheses", Bernardo, J. M., DeGroot, M., Lindley, D. and Smith, A.F.M. (Eds), Bayesian Statistics 1, Univeristy Press, Valencia, pp. 585-603.

Zellner, A. and Siow, A. (1984), Basic Issues in Econometrics, University of Chicago Press, Chicago.

Zhou, K. and Wong, M.C. (2008), "The determinants of net interest margins of commercial banks in mainland China", Emerging Markets Finance and Trade, Vol. 44 No. 5, pp. 41-53.

\section{Corresponding author}

Jesús Peiró-Palomino can be contacted at: jesus.peiro@uv.es

\section{Profitability in the banking industry}

For instructions on how to order reprints of this article, please visit our website:

www.emeraldgrouppublishing.com/licensing/reprints.htm

Or contact us for further details: permissions@emeraldinsight.com 